\title{
O USO DA CONTRADIÇÃO NO DISCURSO DO HISTORIADOR GILFRANCISCO PARA REESCREVER A LITERATURA SERGIPANA
}

Thiago Martins Prado

RESUMO: O artigo mapeia os projetos de historiografia literária sergipana destacando as diferenças propostas pela escrita do crítico Gilfrancisco, que sugere o elogio ao caráter acidental da história, com o reconhecimento de sua inevitável característica contraditória, de sua condição fragmentária e de suas potenciais lacunas. Ao serem entendidos os estudos de história da literatura de Gilfrancisco como apresentações da fortuna crítica, da documentação e de demais fontes dos autores em Sergipe por meio de uma perspectiva multidirecional que não elimina a pluralidade de interpretações e as contradições manifestas, objetiva-se mostrar como o crítico problematiza noções como personalidade literária. Para isso, descrições do método de análise da historiografia literária de Gilfrancisco são realizadas neste artigo e, como resultado, discute-se como as técnicas desenvolvidas pelo crítico se articulam com as tendências atuais sobre estudos de documentação.

PALAVRAS-CHAVE: Gilfrancisco; Historiografia literária; Uso da contradição.

ABSTRACT: Such an article is based upon projects of literary historiography in Sergipe which stress the different proposals by Gilfrancisco's writing who is a critical. He proposes the compliment for the accidental character of the history with the recognition of his contradictory characteristic inevitable as well as his fragmented characteristic and his potential gaps. The studies of Gilfrancisco's literature history are understood while presentations of critical fortune as well as the documentation and other sources of authors in Sergipe. It is made by means a multidirectional perspective which does not eliminate interpretation plurality and the obvious conflicts which have the aim of showing like the critic concerns notions like literary personality. Due to such a thing, Gianfrancisco's literary historiography analysis method descriptions are carried out in such an article and as a result, the techniques which are developed by critic are discussed on how they are articulated with up- to- date tendencies about documentation studies.

KEYWORDS: Gilfrancisco; Literary historiography; Contradiction use. 


\section{INTRODUÇÃO}

Com estudos de diversos escritores sergipanos, o pesquisador Gilfrancisco desafiou a tradição da historiografia literária em Sergipe ao valorizar as perspectivas microscópicas de diversas de suas fontes utilizadas. Sua técnica deriva da não eliminação do caráter contraditório, múltiplo ou lacunoso que compõe as vivências dos escritores investigados, permitindo uma interpretação plural e distante dos perfis congelados e consagrados pela historiografia tradicional. Nesse sentido, alimentar as contradições, no discurso da historiografia de Gilfrancisco, é respeitar a multiplicidade de vozes que tentam enunciar, com os meios e as formações que lhes são cabíveis, outras histórias possíveis. Embora o projeto de escrita da história de Gilfrancisco não mais enuncie uma orientação central ou uma verdade histórica capazes de articular os diversos agrupamentos socioculturais, ele apresenta possibilidades de narrativas e significados históricos dentro das próprias diversidades, diferenças e inevitáveis conflitos e contradições.

A historiografia literária de Gilfrancisco transita predominantemente pelos estudos da literatura baiana e da sergipana. Como um dos seus projetos mais ambiciosos, a Coleção BASE por ele fundada acolhe críticas sobre escritores desses dois estados. Em meio a tantas investigações desse estudioso baiano a respeito da literatura regional, o que interessa neste artigo é verificar qual a metodologia da escrita da história que Gilfrancisco impõe para a literatura sergipana.

\section{ANTECEDENTES DA HISTORIOGRAFIA LITERÁRIA SERGIPANA}

Quando focamos nos projetos de historiografia literária em Sergipe, observaremos alguns casos bem representativos. O maior deles deve-se a Jackson da Silva Lima, também muito conhecido como folclorista. Nos dois volumes de História da literatura sergipana, ${ }^{1}$ Silva Lima adota uma perspectiva centrada na valorização de personalidades literárias como se fossem identidades já plenamente consolidadas. Dessa forma, a importância da personalidade é presumida como indiscutível pela lógica desse projeto. Com a visão da historiografia literária apoiada no agrupamento de personalidades literárias

1 LIMA, Jackson da Silva. História da literatura sergipana, vol. 1. Aracaju: Livraria Regina, 1971; História da literatura sergipana vol. 2. Aracaju: Governo do Estado de Sergipe, 1986. 
em compartimentalizações de escolas, o molde dos estudos de Jackson da Silva Lima apresenta-se deveras conservador. Nesse sentido, todos os autores catalogados (personalidades literárias) devem ser reduzidos aos valores dos movimentos literários para poderem se encaixar como representantes da escola. Muitas outras interpretações possíveis sobre a existência literária do autor ou da sua obra acabam por ser retiradas. Além disso, o conceito de escolas literárias torna menores e subalternas em relação a referências europeias as literaturas regionais. A lógica de se organizar o saber estético em forma de escolas iniciou-se como uma prática europeia e sustentou a autoridade e superioridade forjadas no eurocentrismo como pontos de irradiação de cultura estética e erudita, que repassavam as tendências necessárias à atualização de suas colônias ou ex-colônias. As obras da literatura regional sergipana, nesse caso, ao se considerar essa escala importada de valores, acabam se enquadrando na condição de cópias menos qualificadas por sua própria dependência cultural. Dessa tentativa de justificar o valor universal da literatura por meio de uma estrutura que reforça as diferenças econômicas, nota-se um desconforto dos escritores de literaturas regionais que estão à margem dos centros de poder. Embora, muitas vezes, afirme-se a peculiaridade da literatura não metropolitana, o espelho que se finca e que se estabelece como referência maior e principal reflete os padrões das metrópoles, entendidos como originários e motivadores de tendências. Por fim, com esse organograma a sustentar a historiografia literária, a literatura regional somente pode ser entendida como uma propagação de uma literatura maior. Os intérpretes locais (personalidades literárias) da literatura regional à margem, portanto, assumiriam compromissos pela continuidade dos laços com os centros de irradiação de movimentos estéticos em países subdesenvolvidos. Associada a essa invenção de sentimento de pertença da literatura de países periféricos às dos centros de irradiação de movimentos estéticos, a ilusão de autonomia do sistema literário, fórmula que distancia os valores da literatura das suas motivações socioeconômicas, impôs uma série de restrições tanto na produção quanto na recepção das obras locais. Ao se interpretarem as literaturas regionais como reflexos das literaturas metropolitanas europeias, determina-se um ritmo de produção local assim também como a adoção dos critérios de avaliação para tais obras.

Outro projeto de historiografia literária sergipana está encaixado dentro da História política de Sergipe. Um estudioso chamado Ariosvaldo Figueiredo ${ }^{2}$ reúne uma

2 Figueiredo, Ariosvaldo. História política de Sergipe, vol. 5. Aracaju: Ed. Autor, 1990; História política de Sergipe, vol. 6. Aracaju: Ed. Autor, 2000. 
série de fontes, principalmente jornalísticas, para defender um valor de justiça ou de verdade por meio da articulação dessas fontes, a fim de corroborar seu sistema ideológico. Nesse caso, todo o conjunto literário, no sentido de reconhecimento de escritores, produção e crítica, aparece como recortes da visão política de Ariosvaldo Figueiredo. Essa visão macroscópica da política (com uma antecipação de um juízo superior) absorve os entremeios da própria micropolítica que existem no estado de Sergipe e que não são discutidos adequadamente, pois ocorre um conceito de verdade (uma redução discursiva) nesse estudo que impera e articula todas as interpretações do cenário sociopolítico e também outras produções da cultura, como a literatura. O escopo de Ariosvaldo Figueiredo, uma coleção monumental que contava com seis grossos volumes na entrada dos anos 2000, acaba por apresentar, paralelamente à escrita da trajetória política do estado de Sergipe, uma história da literatura sergipana como um recorte de uma ideologia política específica - com uma avaliação baseada também no ideal que move tal ideologia.

Como outro projeto de historiografia literária sergipana que merece atenção, o primeiro estudo no estado a desafiar o conceito de autonomia estética pertence a Austrogésilo Santana Porto, com o livro O realismo social na poesia em Sergipe, publicado no ano de $1960 .{ }^{3}$ Santana Porto reconhece que o objeto estético, estando num discurso de autonomia, evoca uma pretensão (falsa) de ser um sistema à parte dos conflitos sociais - quando, em verdade, boa parte do fenômeno literário pode ser compreendida como resultado desses conflitos, assim como há um emaranhado de lutas simbólico-sociais ocorrendo dentro da própria literatura. O problema dessa publicação de Austrogésilo Santana Porto reside nos critérios de avaliação intrinsecamente ligados a uma forma de pensar a estética pela filosofia marxista. Nesse sentido, $O$ realismo social na poesia em Sergipe valorizava a obra de escritores, muitas vezes, com base em questões biográficas; ou seja, quanto mais o autor estivesse próximo das camadas desfavorecidas (origem humilde) ou expressasse essa proximidade, mais chances ele teria de receber uma crítica elogiosa. Outra forma de avaliação embasava-se em verificar o nível de confiança ou otimismo nos projetos socialistas. Tendo como um dos critérios de uma boa arte a necessidade de expressão da certeza de que realmente o comunismo seria implantado no país, a literatura serviria como combustível de esperança para a

3 PORTo, Austrogésilo Santana. O realismo social na poesia em Sergipe. Aracaju: Livraria Regina, 1960. 
propagação do pensamento político marxista. Acontece que essa forma de escrita da história da literatura de Sergipe é fruto de um contexto histórico muito específico, ela surge como um reflexo da utopia sociopolítica sessentista, um ideal de uma máxima representação de coesão sócio-histórica - que hoje já não é mais possível. Tal modo de conceber a literatura edificou o discurso estético como uma maneira de arregimentação política e arrasou a atividade artístico-literária como evento criativo. O realismo social na poesia em Sergipe, ao cobrar a proximidade com as camadas populares e a certeza na causa revolucionária, acaba por escravizar escritores e críticos quanto às formas de produção e avaliação estéticas.

Nos tempos hodiernos, as grandes narrativas sociológicas que embasaram esses projetos de historiografia literária sergipana declinaram. Há uma desvalorização da metafísica ocidental e uma desconfiança na qualificação do saber como matéria perene, serena e universal. Na contemporaneidade, esse saber é compreendido como ferramenta do discurso totalitário e opressor. Portanto, não foi à toa que o projeto de Jackson da Silva Lima, depois de minuciosamente esquematizado nos anos 1970 no volume 1 , foi interrompido no volume 2, em meados dos anos 1980. Com esse contexto, não havia nenhuma lógica em se defender uma linha da história literária. $\mathrm{O}$ fim da história da literatura é que mereceria destaque, já que ela foi associada a uma concepção evolucionista e causalista, em que se sacrificam diversos autores enquadrando-os numa só escola e negando ou esquecendo um número incalculável de interpretações possíveis e cabíveis às suas obras. Esse tipo de saber, desse modo, mostrou-se totalitário e opressor.

De igual modo, houve também um declínio das certezas quanto aos discursos de verdade ou de justiça como versões unilaterais. Atualmente, defende-se a multiplicidade das verdades ou dos modos de encarar o que é ser justo em meio à preocupação contemporânea a respeito de um plano de tolerância e de coabitação de verdades ou justiças. As certezas nas conquistas sócio-históricas, impulsionadas pelas metanarrativas da modernidade, ou se mostraram fracas, ou se mostraram tirânicas.

A escrita ampla da macro-história, que pretende traduzir todos os fatos por meio de uma orientação sociopolítica, somente pode ser entendida como uma redução da interpretação histórica. Esse pode ser o ponto crucial que determina o questionamento de estudos como os de Ariosvaldo Figueiredo e Austrogésilo Santana Porto, pois quem defende uma certeza sociopolítica suprime a multiplicidade do próprio olhar. Quem defende uma logicidade inerente à escrita da macro-história não consegue visualizar que a história é composta de contradições e de inevitáveis incoerências, próprias das condições culturais. 
É preciso o historiador contemporâneo afastar-se do elogio à razão, iniciada desde o mandamento aristotélico de não contradição para a instrução do saber; é preciso que o historiador compreenda que o saber nasce da contradição e também é fruto de incoerências. Contemporaneamente, quem fala em nome da justiça, da liberdade ou da verdade deve ser visto com desconfiança. Isso porque a defesa dos universais e da igualdade destruiu o respeito às diferenças, escravizando homens e pensamentos ou ainda os excluindo.

\section{A HISTORIOGRAFIA LITERÁRIA SERGIPANA PROPOSTA POR GILFRANCISCO}

Novos rumos para a historiografia literária sergipana que se articulassem com as discussões da contemporaneidade só se deram com um escritor baiano chamado Gilfrancisco, apelidado de índio por seus traços físicos a confirmar sua ascendência próxima. Estando em trânsito entre Bahia e Sergipe a todo instante como jornalista, Gilfrancisco publicou vários livros que tematizam as literaturas regionais dos dois estados. Seu livro mais importante e mais comentado dentro da historiografia literária sergipana é Flor em rochedo rubro: o poeta Enoch Santiago Filho. ${ }^{4}$

Numa leitura apressada, Flor em rochedo rubro parece dar continuidade à metodologia dos outros projetos de historiografia literária já experienciados no estado de Sergipe, já que se vale de coletas de dados em periódicos e documentos esparsos para orientarem enredos para a história literária. Como esses enredos são construídos é o que diferencia os trabalhos de Gilfrancisco dos outros estudos vinculados às concepções de modernidade. $\mathrm{O}$ índio Gilfrancisco realiza um elogio à diferença e ao caráter acidental da história, assim também como caracteriza a escrita da história como um processo de descontinuidade (e não de evolução ou amarrada a uma lógica causalista) - isso se evidencia em seus estudos sobre Alina Paim, Ranulfo Prata, Enoch Santiago Filho etc. A organização dos livros de Gilfrancisco afirma uma metodologia da escrita da história que não se prende a uma concepção de defesa ideológica da verdade, de justiça, ou que se fincasse a um conceito de universalidade.

4 GILFRANCISCO. Flor em rochedo rubro: o poeta Enoch Santiago Filho. Aracaju: Secretaria de Estado da Cultura, 2005. 
Por um lado, o recorte que impera na escrita da história de Gilfrancisco é sempre microscópico. Nas obras de Gilfrancisco, não se nota a ambição redutora de se alargar a diversos autores ou a momentos históricos - a perspectiva de suas obras concentra-se no autor como processo de experiências que o fez um fenômeno literário. Por outro lado, Gilfrancisco usa multilateralmente as fontes pesquisadas, ou seja, as fontes não são utilizadas para defender um discurso único ou uma versão mais verdadeira da história. As fontes são colocadas lateralmente de maneira a apontar para possibilidades diversas de reescrita da história. $\mathrm{O}$ estudioso Gilfrancisco, dessa forma, mostra que a personalidade literária é fruto de uma montagem, logo a proposta dele passa a ser a investigação de como o discurso crítico consolidou o fenômeno gerador da personalidade literária para o autor ora pesquisado. Todo o encaminhamento da historiografia proposta por Gilfrancisco acaba por ser uma análise e uma ilustração dos rituais de consagração das personalidades literárias e dos entremeios que possibilitaram publicações ou formações da recepção crítica. $\mathrm{O}$ índio Gilfrancisco entende a história como uma narrativa de ímpeto ficcional - tal como Hayden White ${ }^{5}$ defendeu. A história possui diversos recursos narrativos e, para se construir uma valência emocional (o heroísmo da verdade ou da justiça, a tragédia do mártir ou do silenciado, por exemplo), é necessário que os conectivos dos fatos e as imagens atribuídas de valor sejam, portanto, enredados.

Com essa interpretação, Gilfrancisco aponta para uma questão: a personalidade literária em nenhum momento de suas etapas de formação (produção ou recepção) é consolidada. A personalidade literária é entendida como resultado de uma filtragem de valores da recepção crítica, com exclusão e recombinação de algumas imagens (por onde a fortuna crítica já passou) pertinentes ao crítico ou ao historiador, imbuídos de códigos socioculturais de seu contexto histórico. Gilfrancisco, com seus estudos, realiza uma desconstrução da personalidade literária como um evento acabado e bem definido a habitar nossos livros de história da literatura, ou seja, uma redução discursiva para a construção de uma coerência ideológica.

O que o historiador Gilfrancisco, em sua experiência de jornalista e arquivista, obriga-nos a constatar é que existem potenciais lacunas que o discurso final sobre a personalidade literária não permitiu por uma necessidade de transparência e coerência (urgências preenchidas de códigos socioculturais). Gilfrancisco, logo, ao colocar diversas fontes contraditórias uma ao lado da outra, descarta, na contemporaneidade, a

5 white, Hayden. Trópicos do discurso. São Paulo: Edusp, 1994. 
coerência como valor a orientar a escrita da história. O resultado de um sujeito literário que seja coerente, nesse sentido, só pode ser fruto da violência.

A historiografia literária de Gilfrancisco induz-nos a observar a incoerência e a contradição nos rumos da história para notar a possibilidade e a multiplicidade de discursos silenciosos que não afloraram ou que foram esquecidos diante da formulação final da imagem dos escritores. Desse modo, o índio Gilfrancisco cumpre a tarefa preconizada pelo filósofo Walter Benjamin: "escovar a história a contrapelo" - nesse caso, voltar às dinâmicas de construção das personalidades literárias para verificar o que foi colocado de fora, excluído ou silenciado, e o que foi considerado.

A obra de Gilfrancisco também demonstra um respeito à condição fragmentária do sujeito que escreve. $\mathrm{O}$ autor não é monolítico, ele tem diversas fases, tem diversas contradições dentro dele. Há também um respeito pela provisoriedade do saber, pois todo saber está articulado ao seu contexto. Se determinado crítico impôs um valor específico a determinado autor ou à sua obra, no futuro, tal consideração tombará frente a uma nova versão de outro crítico, pertencente a outro contexto de fala (também provisório). Com essa consideração, Gilfrancisco não expurga a própria provisoriedade da sua historiografia.

Nesse âmbito, os estudos de Gilfrancisco não atuam como sistemas fechados - não se parte de uma estrutura simbólico-analítica prévia ou de alguma imagem de orientação sociopolítica. Nenhum livro de Gilfrancisco privilegia a definição como resultado do trabalho de investigação. Um crítico chamado Antônio Carlos Barreto ${ }^{7}$ chega a essa mesma conclusão quando afirma que os textos de Gilfrancisco não são conclusivos, eles são mais problematizadores que definidores.

A aceitação da contradição, a demonstração da inconsistência na costura da história e a desvalorização de definições para o trabalho historiográfico, antes de serem consideradas uma fragilidade no discurso de Gilfrancisco, instrumentalizam um novo rumo para a historiografia literária no estado de Sergipe.

6 BENJAMIN, Walter. Obras escolhidas, vol. 1: magia e técnica, arte e política: ensaios sobre literatura e cultura. São Paulo: Brasiliense, 1985.

7 Barreto, Antonio Carlos de Oliveira. "Poemas: Enoch Santiago Filho". Jornal da Cidade, Aracaju, 26 abr. 2006, p. C-2. 


\section{CONSIDERAÇÕES FINAIS}

Quais são as tendências atuais dos estudos de documentação que se articulam à proposta de outra historiografia literária por Gilfrancisco? Primeiro, Gilfrancisco renuncia a todo e qualquer projeto totalizante. Não há uma ideologia marxista, como em Austrogésilo Santana Porto, um conceito de verdade ou de justiça, como em Ariosvaldo Figueiredo, ou um valor de universalidade que atinja um julgamento do sistema literário como um todo, tal qual em Jackson da Silva Lima, que justifiquem a apreensão da história da literatura como uma trajetória unilateral.

Segundo, há uma busca por testemunhos que estejam silenciados nos escombros. Por exemplo, é digna de nota a investigação de Gilfrancisco a respeito da romancista Alina Paim, ${ }^{8}$ figura literária que se consolidou como uma feminista da esquerda transitando entre Bahia e Sergipe. O primeiro romance de Alina Paim, chamado Estrada da liberdade, deve boa parte de seu sucesso à compra dos exemplares pelas freiras para que pudessem ser queimados. Como feminista implacável, no seu romance Simão Dias, ela expôs as famílias poderosas da região e isso trouxe graves problemas para ela também. No entanto, essa é a imagem consolidada da romancista. Gilfrancisco observou que, depois de determinado tempo, essas pessoas que serviram para compor as personalidades literárias para o estudo crítico ou historiográfico, acabam sendo retiradas do processo já consolidado. As personalidades literárias (distantes das pessoas que lhes deram base) atuam como entidades que não podem ser tocadas pelo material da existência dos autores correspondentes a elas - a personalidade literária, por fim, resulta de um processo de desumanização. Praticamente, ninguém do meio literário tinha conhecimento de que Alina Paim, aos 88 anos quando Gilfrancisco realizou uma entrevista com a romancista, morava no Mato Grosso e estava com um problema sério de acuidade visual, isto é, ela foi esquecida e a sua imagem como personalidade literária sobreviveu como parasita de si. Muitas vezes, Gilfrancisco repete tal procedimento: ele tenta resgatar um contato pessoal que complemente, desvirtue, reatualize ou até mesmo negue a imagem que foi imposta pela historiografia literária oficial.

Terceiro, Gilfrancisco evita o unilateralismo discursivo. O estudioso abre suas fontes tal como se fossem vozes múltiplas a chocarem-se muitas vezes e a entrarem em inevitável contradição sem execução de cortes nos documentos recolhidos. Quarto, a

8 gilfrancisco. A romancista Alina Paim. Aracaju: Funcaju, 2007. 
crítica do índio Gilfrancisco valoriza saberes provisórios. Em Flor em rochedo rubro, como ilustração, Gilfrancisco apresenta a interpretação humanista de Zitelman de Oliva sobre o poeta Enoch Santiago Filho, logo após a Segunda Grande Guerra, quando ainda se preconizava um valor de união dos povos acima da distinção entre capitalismo e comunismo. Em 1960, Gilfrancisco mostra como a crítica a respeito da obra de Enoch mudou radicalmente: Austrogésilo Santana Porto colocou o poeta no centro da dicotomia entre capitalismo estadunidense e comunismo soviético - elogiando os cantos marxistas que os seus poemas traziam. Como desdobramento posterior, Gilfrancisco traz os comentários de Eunaldo Costa, nos anos 1980, que indicam a falta de maturidade de Enoch Santiago Filho por exatamente estarem vinculados à filosofia de Karl Marx. Nesse exemplo, documentam-se críticas completamente diferentes e contraditórias colocadas lado a lado. Além disso, em Flor em rochedo rubro, Gilfrancisco aponta para diversos poemas de Enoch Santiago Filho com que a fortuna crítica, ao tentar mapear a orientação política de sua produção, ainda não se deparou. Se se falar da poesia de Enoch Santiago Filho concentrando-se meramente na motivação de sua recepção crítica, nota-se uma discussão démodé. Em verdade, Gilfrancisco sinaliza que, ao contrário de uma produção fora dos tempos, Enoch Santiago Filho recebeu críticas marcadas por uma sabedoria provisória e que se atualizaram a todo instante conforme a perspectiva ideológica do seu comentador.

Por último, Gilfrancisco narra a história como um sistema aberto e multicombinatório. Dessa forma, Gilfrancisco inverte o privilégio de um resultado bem definido e bem acabado como conclusão e fechamento de um estudo de fontes para um outro de reconhecimento de aberturas múltiplas e infinitas das possibilidades discursivas da recepção crítica.

Gilfrancisco observa que a coerência dos dados da história só pode ser fruto de um fingimento, de uma redução da história. Para Gilfrancisco, a natureza da história é feita de contradições e incoerências, e fingir coerência seria, portanto, sinônimo de violentar, pensar num tempo homogêneo ou acreditar numa só interpretação para a história. Essa historiografia alerta de que é preciso reinstalar as dinâmicas do passado e, para isso, torna-se urgente reencontrar as contradições e reviver as incoerências.

Thiago Martins Prado é Professor Adjunto da Universidade do Estado da Bahia 